\title{
AN APPLICATION OF BUBBLE COLLAPSE PULSE HEIGHT SPECTRA TO VENTURI CAVITATION EROSION OF 1100-O ALUMINUM
}

\author{
SHUJI HATTORI*, BONG-HWA SUN and FREDERICK G. HAMMITT \\ Department of Mechanical Engineering and Applied Mechanics, Cavilation and Multi- \\ phase Flow Laboratory, University of Michigan, Ann Arbor, MI 48109 (U.S.A.)
}

TSUNENORI OKADA

Department of Mechanical Engineering, Fukui University, Fukui (Japan)

(Received October 11, 1984; accepted April 15, 1985)

\section{Summary}

Venturi cavitation erosion tests were performed and correlated with bubble collapse pulse height spectra measured by a microtransducer. The effects of the throat velocity and the cavitation number $\sigma$ (referred to the downstream pressure and throat velocity) on the erosion rate (MDPR) were studied. The velocity damage exponent was 4.11 for $0.62 \leqslant \sigma \leqslant 0.80$, while the MDPR is almost independent of velocity for $\sigma=0.85$. The MDPR decreases with increased $\sigma$ for $0.62 \leqslant \sigma \leqslant 0.85$. The data were reduced to "acoustic power" (from pulse height spectra) and "erosion power" (the ultimate resilience multiplied by the MDPR). A near-linear relationship was found between these. Their reciprocal ratio $\eta_{\mathrm{cav}} \approx 7 \times 10^{-11}$. For $\sigma=$ 0.62 , the data deviated from the others, possibly because of the work hardening of the eroded surface.

\section{Introduction}

One of the major present problems for cavitation research is the almost complete inability to predict field erosion rates, or even their probable existence, from existing laboratory tests [1]. One possibility to help overcome this difficulty is to measure and count individual bubble collapse pressure pulses and to correlate this result with measured erosion rates from the same facility. Such a study has been previously made [2-4], and results have been presented in terms of "acoustic power" and "erosion power". Erosion power is defined as the power needed to erode the material and to cause the observed pitting or volume loss. The reciprocal ratio

*Previously on leave from the Department of Mechanical Engineering, Fukui University, Fukui, Japan. 
(i.e. the erosion power divided by the acoustic power) between these quantities was termed the "cavitation erosion efficiency" $\eta_{\text {cav }}$. This was found to be essentially constant: $\eta_{\text {cav }} \approx 6.8 \times 10^{-11}$ over a very limited test range for 1100-O aluminum [2]. These tests were conducted in the University of Michigan Venturi facility (Fig. 1), which was also used in the present tests.

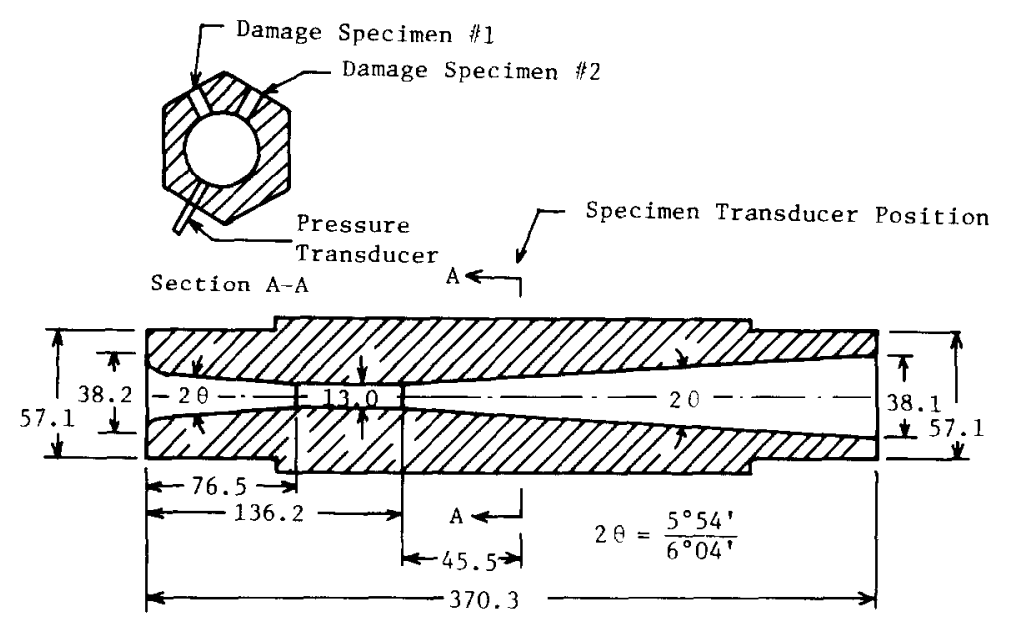

Fig. 1. Venturi details.

The present study was undertaken to examine the applicability of this method for predicting erosion rates for various cavitation flow conditions. Tests were conducted at two throat velocities ( 36.3 and $49.0 \mathrm{~m} \mathrm{~s}^{-1}$ ) under cavitation numbers $\sigma=0.62,0.70,0.80$ and 0.85 , defined with reference to downstream pressure and throat velocity $\left(\sigma=\left(p_{\mathrm{d}}-p_{\mathrm{v}}\right) / \frac{1}{2} \rho V^{2}\right.$ where $p_{\mathrm{d}}$ is the downstream pressure, $p_{v}$ the vapor pressure, $V$ the throat velocity and $\rho$ the liquid density). Bubble collapse pulse height spectra (PHS) were measured using the already-developed system [2-4]. PHS results reduced to acoustic power were compared with erosion power measured on test specimens inserted in the diffuser region (Fig. 1).

\section{Experimental procedures}

The cavitation tests were performed in a high speed closed-loop Venturi tunnel. The cylindrical Plexiglas Venturi (Fig. 1) has a throat diameter of $12.7 \mathrm{~mm}(0.5 \mathrm{in})$ and a $6^{\circ}$ total cone angle around a cylindrical throat section. Two specimens, located in the same axial plane, were tested simultaneously (Fig. 1, specimens 1 and 2). A microtransducer was located in the same axial plane. The test liquid was Ann Arbor tap water at about $26.7^{\circ} \mathrm{C}\left(80^{\circ} \mathrm{F}\right)$, which was degassed by a cold water vacuum deaerator before each test to a total air content moderately below saturation at standard temperature and pressure. 
The specimens and microtransducer (Kistler model 601A) were mounted flush with the diffuser wall in the general region of cavitation bubble collapse as determined visually (Fig. 1). Of course, the cavitation cloud length depends to some extent on $\sigma$ and $V$. The approximate extent of cavitation ("cavitation condition") is set by adjusting the downstream pressure for a fixed velocity, which was determined from flow measurement. The specimen material was $1100-0$ aluminum (commercially pure annealed aluminum) machined from bar stock of $6.35 \mathrm{~mm}(0.25 \mathrm{in}$ ) diameter (Fig. 2). The cavitated surface was polished before the tests with emery papers of successively finer grades (to grade 600). Mass loss versus time tests were performed to measure the mean depth of penetration rate (MDPR) (i.e. the volume loss rate divided by the area) for various flow conditions (Figs. 3 and 4).

Details of the bubble collapse PHS acquisition system are reported elsewhere [2].

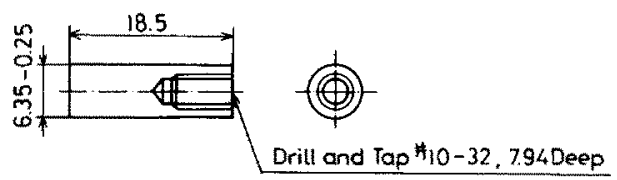

Fig. 2. Venturi erosion specimen.

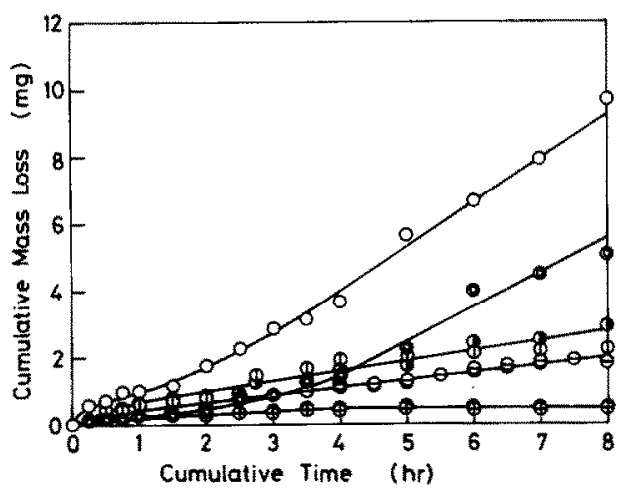

Fig. 3. Cumulative mass loss vs. time $\left(V=49.0 \mathrm{~m} \mathrm{~s}^{-1}\right.$; uncertainty in cumulative mass loss, $\pm 0.05 \mathrm{mg}$ ).

\begin{tabular}{lll}
\hline$\sigma$ & \multicolumn{2}{c}{ Symbol for the following specimens } \\
\cline { 2 - 3 } & Specimen 1 & Specimen 2 \\
\hline 0.62 & 0 & 0 \\
0.70 & 0 & 0 \\
0.80 & $\ominus$ & $\bullet$ \\
0.85 & $\oplus$ & $\bullet$ \\
\hline
\end{tabular}




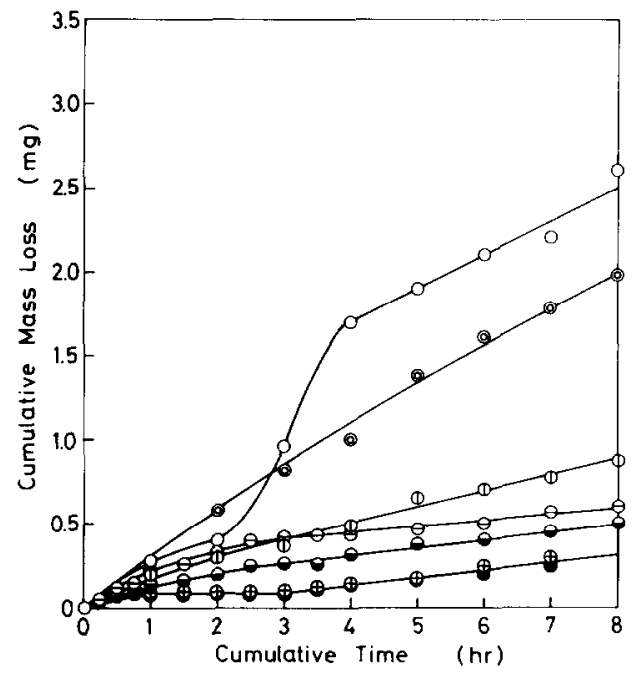

Fig. 4. Cumulative mass loss $v s$. time ( $V=36.3$ and $26.0 \mathrm{~m} \mathrm{~s}^{-1}$; uncertainty in cumulative mass loss, $\pm 0.05 \mathrm{mg}$ ).

\begin{tabular}{llll}
\hline $\begin{array}{l}V \\
\left(\mathrm{~m} \mathrm{~s}^{-1}\right)\end{array}$ & $\sigma$ & \multicolumn{2}{c}{ Symbol for the following specimens } \\
\cline { 2 - 4 } 36.3 & & Specimen 1 & Specimen 2 \\
& 0.62 & $\odot$ & $\circ$ \\
26.0 & 0.70 & $\oplus$ & $\bullet$ \\
\hline
\end{tabular}

\section{Experimental results and discussions}

\subsection{Mass loss tests}

The cumulative mass loss versus time under various cavitation conditions is shown in Figs. 3 and 4. Tests were carried to total duration of $8 \mathrm{~h}$, and specimens were weighed at least hourly. Curves for specimens 1 and 2 distinguish results from the two specimens located at the same axial but different angular positions. Marked rate differences between specimens 1 and 2 occurred, especially for low $\sigma$. Similar results had been found previously [4-6]. Thus these differences do not result from the present experimental procedure but probably from flow asymmetries due to characteristics of the tunnel and the erosion process.

Effects of $\sigma$ on the mean MDPR (full test duration) at fixed velocity are shown in Fig. 5. In the present tests, the MDPR decreases for increased $\sigma$ for $0.60 \leqslant \sigma \leqslant 0.85$, which is the usual result for most machines (see for example ref. 1). However, damage must vanish for very low $\sigma$ because of the low suppression pressure $p_{\mathrm{d}}-p_{\mathrm{v}}$, even though the number of bubbles is then at a maximum. Therefore, this portion of the curve is hypothesized 

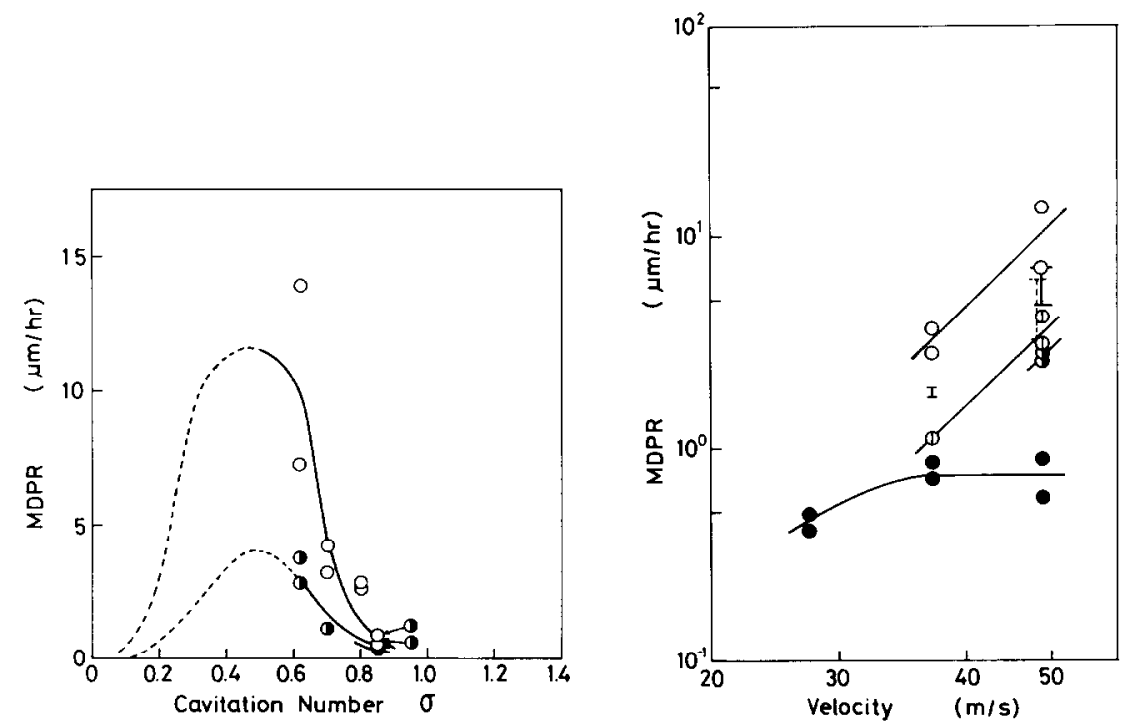

Fig. 5. Effect of cavitation number $\sigma$ on the MDPR (uncertainty in MDPR, $\pm 0.2 \mu \mathrm{m}$ $\mathrm{h}^{-1}$ ): $0, V=49.0 \mathrm{~m} \mathrm{~s}^{-1} ; 0, V=36.3 \mathrm{~m} \mathrm{~s}^{-1} ; \bullet, V=26.0 \mathrm{~m} \mathrm{~s}^{-1}$.

Fig. 6. Effect of velocity on the MDPR (uncertainty in MDPR, $\pm 0.2 \mu \mathrm{m} \mathrm{h}^{-1}$ ): $O, \sigma=$ $0.62 ; \Phi, \sigma=0.70 ; \odot, \sigma=0.80 ; \bullet, \sigma=0.85 ; \mathrm{I}, \sigma=0.56[7] ; \mathrm{I}, \sigma=0.61,0.62[7] ;]_{-}, \sigma=$ $0.76[7]$.

by the broken lines in Fig. 5. This speculation is verified in the vibratory tests (see for example ref. 1).

The velocity effect on the MDPR at constant $\sigma$ was explored (Fig. 6). The logarithmic curve slope is almost the same for $\sigma=0.62$ and 0.70 , giving a "velocity exponent" of 4.11 , which is consistent with our previous results [7]. However, the MDPR for the highest $\sigma$ tested (least developed cavitation) is independent of velocity (discussed later).

Figure 7 shows the effect of $\sigma$ on the cloud length for various velocities. The cloud length increases for decreasing $\sigma$ as expected, almost independently of velocity. This result is consistent with that of other researchers [8]

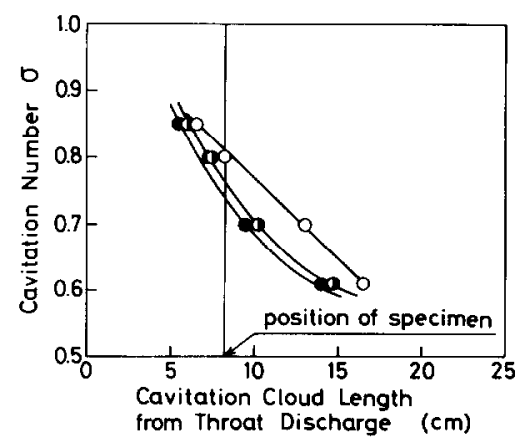

Fig. 7. Cavitation cloud length us. $\sigma$ (uncertainty in cavitation cloud length, $\pm 1 \mathbf{c m}$ ): $O$, $V=26.0 \mathrm{~m} \mathrm{~s}^{-1} ; 0, V=36.3 \mathrm{~m} \mathrm{~s}^{-1} ; \bullet, V=49.0 \mathrm{~m} \mathrm{~s}^{-1}$. 
and, if length is truly velocity independent, it follows "classical" cavitation scaling laws. However, more careful examination (Fig. 7) shows that, for decreased velocity, cloud length does increase to some extent. Thus a cavitation "scale effect" occurs. For $\sigma=0.80$ and 0.85 , the erosion specimens are out of the apparent cavitation cloud for all velocities, while they are well within it for $\sigma=0.62$ and 0.70 . However, high speed photographs (see for example ref. 1) show that more energetic bubbles often penetrate beyond the steady state cloud termination. That erosion damage for $\sigma=0.85$ is almost independent of velocity may be due to the fact that specimens are located downstream of the region of apparent bubble collapse. Damage for low $\sigma$ was much more severe and was heavily dependent on velocity. The usually expected exponent of about 6 was not obtained in these tests, which is consistent with other Venturi tests elsewhere (see for example refs. 1 and 7).

\subsection{Bubble collapse pulse height spectra}

The effects of acquisition time on PHS are shown in Fig. 8. The choice of acquisition time (1-30 min) has little effect (Fig. 8). Since $10 \mathrm{~min}$ suffice to obtain good results, it was chosen to reduce the test time to a reasonable value to assure stable data.

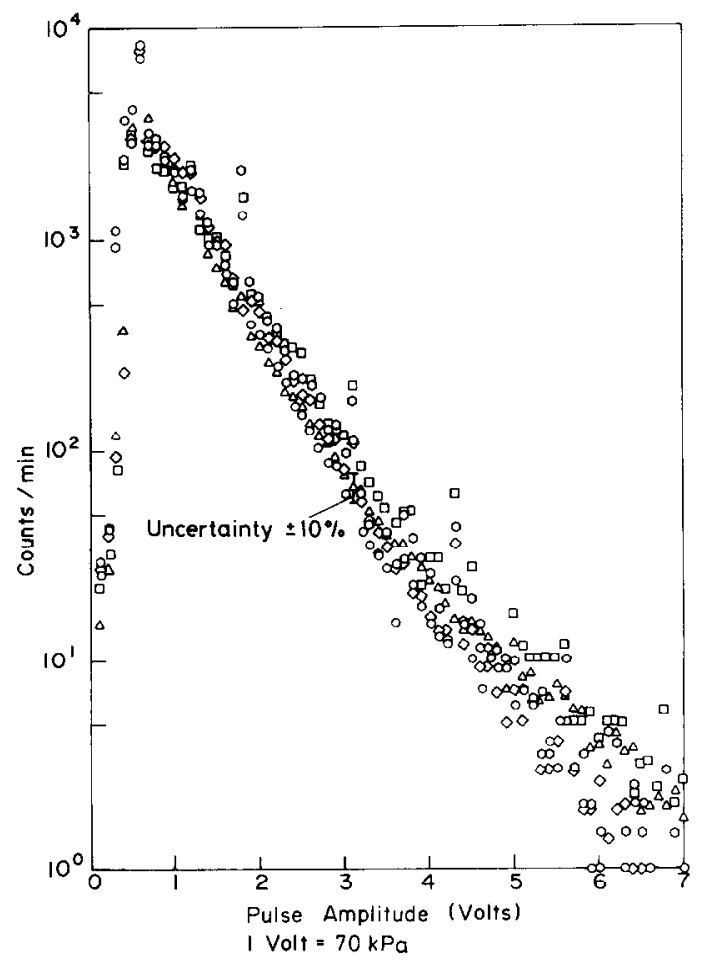

Fig. 8. Effect of data acquisition time $\left(V=36.3 \mathrm{~m} \mathrm{~s}^{-1} ; \sigma=0.70\right): 0,1 \mathrm{~min} ; \emptyset, 2 \mathrm{~min}$; $\diamond, 5 \mathrm{~min} ; \triangle, 10 \mathrm{~min} ; \square, 30 \mathrm{~min}$. 
PHS data under various cavitation conditions are shown in Figs. 9 - 11. While PHS for $\sigma=0.62$ are strongly affected by throat velocity, they are independent of velocity for the higher values of $\sigma(0.80$ and 0.85$)$, which is consistent with MDPR results (Fig. 6).

Acoustic power was calculated from the PHS data. The energy $e$ per unit surface area radiated by a pressure wave is given [9] by

$e=\frac{1}{\rho C} \int_{0}^{\infty}\{p(t)\}^{2} \mathrm{~d} t$

where $C$ is the sonic speed in the liquid, $p(t)$ the instantaneous pressure and $\rho$ the liquid density. An integration time interval $\Delta T$ of $2 \mu$ s was chosen on the basis of high speed photographs of bubble collapse in a similar Venturi [10]. Constant $p$, and thus square pulses, is assumed during this short period. Then eqn. (1) becomes

$e=\frac{\Delta T}{\rho C} p^{2}$

For a large number of bubbles it is assumed that $e$ has a distribution $f_{1}(e)$ so that

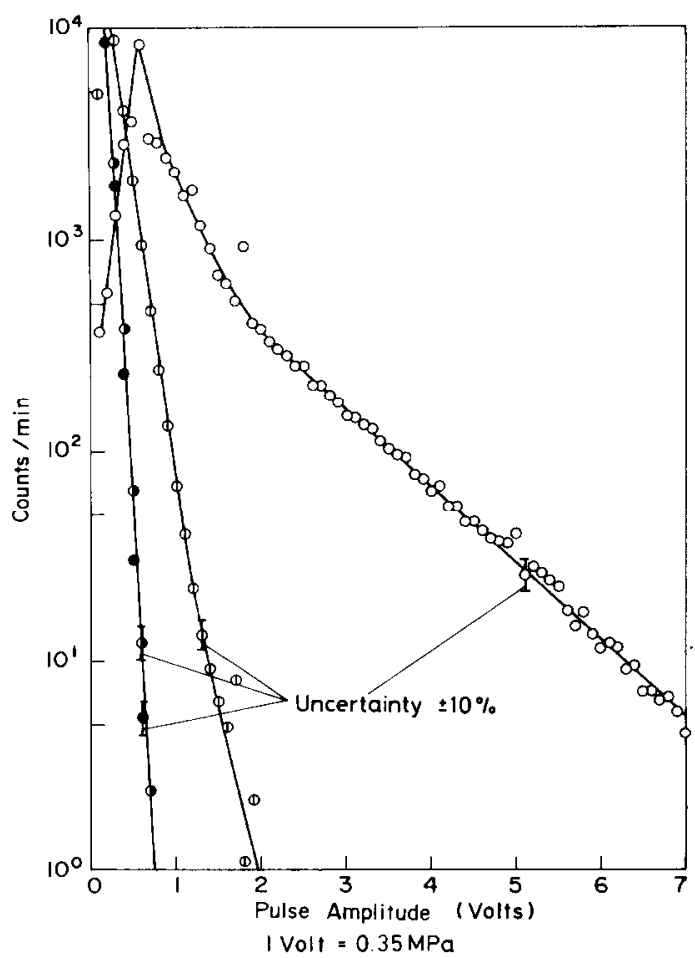

Fig. 9. PHS $\left(V=49.0 \mathrm{~m} \mathrm{~s}^{-1}\right): \bigcirc, \sigma=0.62 ; \oplus, \sigma=0.70 ; \bullet, \sigma=0.80 ; \bullet, \sigma=0.85$. 
$E=\int_{0}^{\infty} e f_{1}(e) \mathrm{d} e$

The distribution $f_{2}(p)$ of $p$ is given by the PHS data (Figs. $\left.12-14\right)$. The next step is then to obtain the relationship between $f_{1}(e)$ and $f_{2}(p)$.

Since $e$ is a monotonically increasing function of $p$ for $e \geqslant 0$ (eqn. $(2)), f_{1}(e)$ is given [11] by

$f_{1}(e)=f_{2}(p)\left|\frac{\mathrm{d} p}{\mathrm{~d} e}\right|$

From eqn. (2),

$\frac{\mathrm{d} p}{\mathrm{~d} e}=\frac{\rho C}{2 p \Delta T}$

and

$f_{1}(e)=\frac{\rho C}{2 p \Delta T} f_{2}(p)$

Substituting eqns. (2) and (5) into eqn. (3), the total energy for a large number of bubble collapses can be given in terms of the pressure distribution:

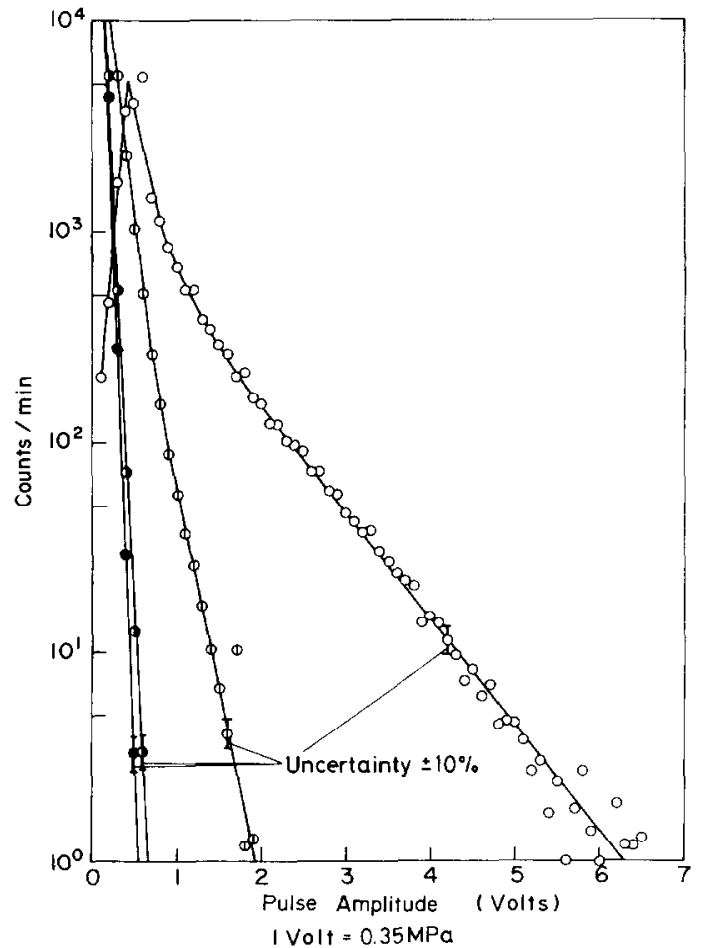

Fig. 10. PHS $\left(V=36.3 \mathrm{~m} \mathrm{~s}^{-1}\right): \odot, \sigma=0.62 ; \odot, \sigma=0.70 ; \circlearrowleft, \sigma=0.80 ; \bullet, \sigma=0.85$. 


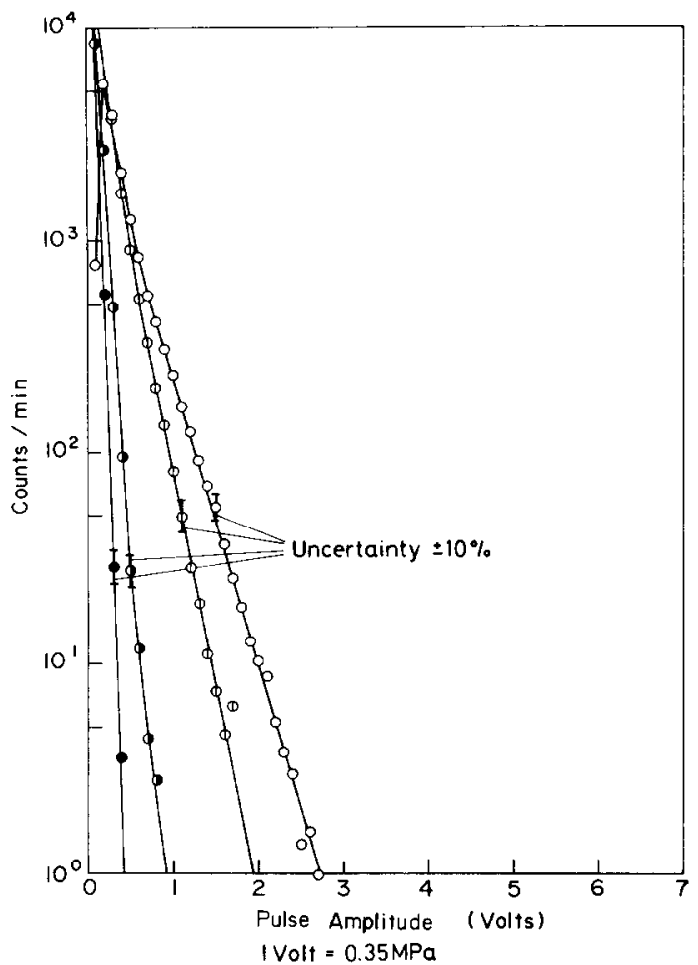

Fig. 11. PHS $\left(V=26.0 \mathrm{~m} \mathrm{~s}^{-1}\right): \circ, \sigma=0.62 ; \Phi, \sigma=0.70 ; \circlearrowleft, \sigma=0.80 ; \bullet, \sigma=0.85$.

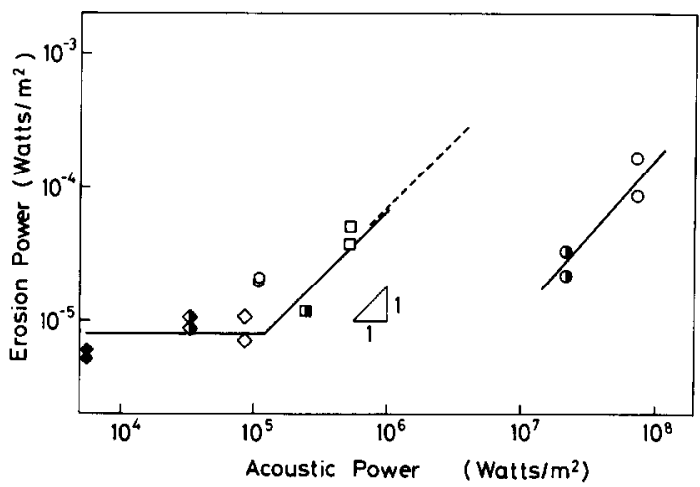

Fig. 12. Relationship between acoustic power and erosion power for 1100-O aluminum $(\cdots$, , after De and Hammitt [2]).

\begin{tabular}{llll}
\hline$\sigma$ & \multicolumn{2}{c}{ Symbol for the following values of $\mathrm{V}$} \\
\cline { 2 - 4 } & $49 \mathrm{~m} \mathrm{~s}^{-1}$ & $36.3 \mathrm{~m} \mathrm{~s}^{-1}$ & $26 \mathrm{~m} \mathrm{~s}^{-1}$ \\
\hline 0.62 & 0 & 0 & \\
0.70 & 0 & & \\
0.80 & 0 & & \\
0.85 & 0 & $\checkmark$ & \\
\hline
\end{tabular}




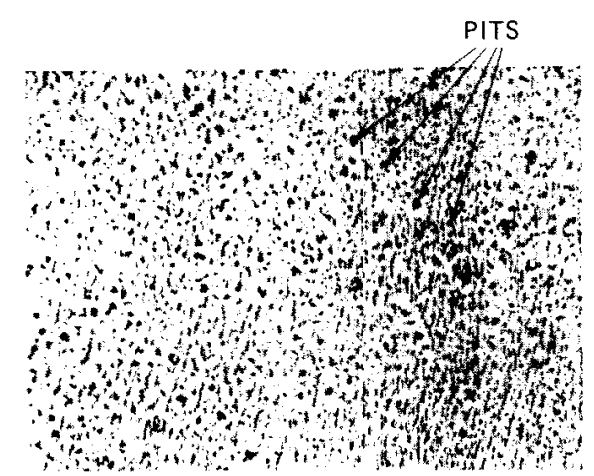

(a)

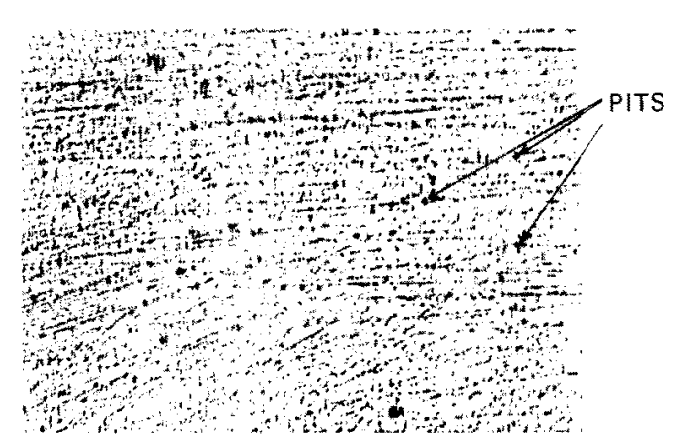

(b)

Fig. 13. Bubble collapse pits for $1100-0$ aluminum (optical microscopy): (a) $36.3 \mathrm{~m} \mathrm{~s}^{-1}$, $\sigma=0.62,1 \mathrm{~min}$; (b) $49.0 \mathrm{~m} \mathrm{~s}^{-1}, \sigma=0.70,10 \mathrm{~min}$. (Magnifications, $70 \times$.)

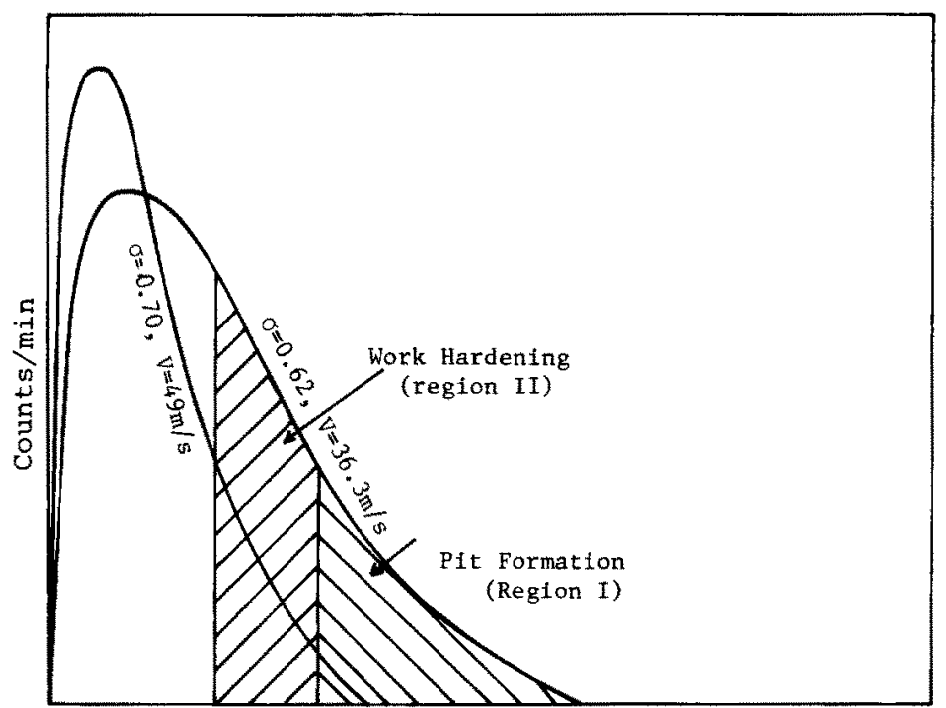

Pulse Amplitude

Fig. 14. PHS.

$E=\frac{\Delta T}{\rho C} \int_{0}^{\infty} p^{2} f_{2}(p) \mathrm{d} p$

Moreover, if $T_{\mathrm{s}}$ is the acquisition time, the acoustic power $P$ is obtained as $P=\frac{E}{T_{\mathrm{s}}}$

$$
=\frac{\Delta T}{\rho C T_{\mathrm{s}}} \int_{0}^{\infty} p^{2} f_{2}(p) \mathrm{d} p
$$


Figure 12 shows the relationship between acoustic power and erosion power on a logarithmic scale. The latter is here defined as the product of the ultimate resilience (the ultimate resilience is given by the tensile strength squared divided by twice the elastic modulus) with the MDPR. Except for $\sigma=0.62$, the data points are approximated by a curve. In the lower acoustic power range below $1.4 \times 10^{5} \mathrm{~W} \mathrm{~m}^{-2}$, the erosion power has almost a constant value. This may be because part of the damage is due to corrosion rather than mechanical erosion. The erosion power increases with acoustic power in the regime above $1.4 \times 10^{5} \mathrm{~W} \mathrm{~m}^{-2}$, having a gradient of about 1 . This means that the erosion power increases linearly with acoustic power, which is consistent quantitatively with our previous result that $\eta_{\text {cav }} \approx 6.8 \times$ $10^{-11}$ (broken line) [2]. Data points for $\sigma=0.62$ deviate substantially from the others.

For example, the number of collapse pulses for $\sigma=0.62$ and $V=36.3$ $\mathrm{m} \mathrm{s}^{-1}$ is much higher over the whole range of amplitudes than that for $\sigma=0.70$ and $V=49 \mathrm{~m} \mathrm{~s}^{-1}$ (Figs. 9 and 10). The eroded surfaces at the beginning of these tests are shown in Fig. 13. The number and size of pits for $\sigma=0.62$ and $V=36.3 \mathrm{~m} \mathrm{~s}^{-1}$ are larger than those for $\sigma=0.70$ and $V=$ $49 \mathrm{~m} \mathrm{~s}^{-1}$. However, the erosion power is almost the same for all these conditions (Fig. 12). A schematic representation combining Figs. 9 and 10 is considered in Fig. 14. If regions I and II are assumed to represent pit formation and work hardening respectively, the total number of pulses for work hardening, as well as for pit formation, is much higher for $\sigma=$ 0.62 and $V=36.3 \mathrm{~m} \mathrm{~s}^{-1}$ than for $\sigma=0.70$ and $V=49.0 \mathrm{~m} \mathrm{~s}^{-1}$. However, pit sizes become smaller for $\sigma=0.62$. The erosion rate remains the same.

It was previously reported that pure aluminum was work hardened by vibratory cavitation [12]. Therefore it is considered that the deviation of the data points for $\sigma=0.62$ may be caused by the work hardening of the eroded surface.

\section{Conclusions} tests.

The following major conclusions can be drawn from these Venturi

(1) The volume loss rate (MDPR) decreases, at constant velocity, with increasing $\sigma$ within the range tested. However, the MDPR increases with velocity for the lower values of $\sigma$ tested $(0.62<\sigma<0.70)$.

(2) The relation between erosion power and acoustic power was approximated by a single curve, except for $\sigma=0.62$. The ratio of erosion power to PHS acoustic power above $1.4 \times 10^{5} \mathrm{~W} \mathrm{~m}^{-2}$ (i.e. the cavitation erosion efficiency $\eta_{\text {cav }}$ ) was about $7 \times 10^{-11}$, which is consistent with the previous result. However, the results for $\sigma=0.62$ deviated substantially from the others. This suggests that work hardening of the eroded surface should be taken into account, if the erosion is to be estimated from the acoustic power. 
(3) In the lower acoustic power range (less than $1.4 \times 10^{5} \mathrm{~W} \mathrm{~m}^{-2}$ ), the erosion power has an almost constant value. This may be because damage was affected substantially by corrosion rather than by mechanical action alone.

\section{Acknowledgments}

Financial support for this work was provided by National Science Foundation Grant ENG 75-2315 and internal University of Michigan Funds.

\section{References}

1 F. G. Hammitt, Cavitation and Multiphase Flow Phenomena, McGraw-Hill, New York, 1980.

2 M. K. De and F. G. Hammitt, New method for monitoring and correlating cavitation noise to erosion capability, J. Fluids Eng., 104 (4) (1982) 434-442; Instruments system for monitoring cavitation noise, $J$. Phys. E, 15 (1982) $741-744$.

3 F. G. Hammitt, M. K. De, J. J. Elenz and E. W. Hunt, Jr., Venturi cavitation bubble collapse pulse spectra and observed pits in soft aluminum, ASME Cavitation Forum, 1978, American Society of Mechanical Engineers, New York, 1978, pp. 31 - 33.

4 F. G. Hammitt and M. K. De, Cavitation erosion of aluminum considering bubble collapse pulse height spectra and cavitation erosion efficiency, Proc. Int. Conf. on Wear of Materials, Dearborn, MI, April $16-18,1979$, American Society of Mechanical Engineers, New York, 1979; Wear, 55 (2) (1979) 221 - 234.

5 F. G. Hammitt, Observations on cavitation damage in flowing system, J. Basic Eng., 85 (1963) 347 - 359.

6 W. J. Walsh and F. G. Hammilt, Cavitation and erosion damage measurement with radio isotopes, Nucl. Sci. Eng., 14 (3) (1962) 217 - 223.

7 J.-g. He and F. G. Hammitt, Velocity exponent and cavitation number for Venturi cavitation erosion of $1100-0$ aluminum and 1018 carbon steel, Wear, 80 (1) (1982) $43-58$.

8 D. V. Chandrasekhara and B. C. Syamala Rao, Effect of pressure on the length of cavity and cavitation damage behind circular cylinder in a Venturi, ASME Paper 72-WA $/ F E-6,1972$ (American Society of Mechanical Engineers, New York).

9 R. H. Cole, Underwater Explosions, Dover Publications, New York, 1965.

10 C. L. Kling and F. G. Hammitt, A photographic study of spark-induced cavitation bubble collapse, J. Basic Eng., 94 (4) (1972) 825 - 833.

11 I. N. Gibra, Probability and Statistical Inference for Scientists and Engineers, Prentice-Hall, Englewood Cliffs, NJ, 1973.

12 C. M. Preece, S. Dakshinamoorthy, S. Prasad and B. Vyas, Proc. 4th Int. Conf. on the Strength of Metals and Alloys, Nancy, 1976, p. 1397.

\section{Appendix A: Nomenclature}

C sonic velocity

$e \quad$ energy per unit area of acoustic wave

$E \quad$ total energy per unit area of acoustic wave for many bubble collapses

$f_{1}(e)$ distribution function of energy $e$ 


$$
\begin{array}{ll}
f_{2}(p) & \text { distribution function of pressure } p \\
p & \text { pressure of acoustic wave } \\
p_{\mathrm{d}} & \text { downstream pressure } \\
p_{\mathrm{v}} & \text { vapor pressure } \\
P & \text { acoustic power } \\
\Delta T & \text { time interval of pressure wave } \\
T_{\mathrm{s}} & \text { sampling period for pulse height spectra } \\
V & \text { throat velocity } \\
\rho & \text { liquid density } \\
\sigma & \left(p_{\mathrm{d}}-p_{\mathrm{v}}\right) / \frac{1}{2} \rho V^{2}, \text { cavitation number }
\end{array}
$$

